\title{
Impeachment, lawfare y fake news en Brasil. Un espejo latinoamericano
}

\author{
Rafael Böcker Zavaro \\ Universitat Rovira i Virgili \\ rafael.bocker@urv.cat
}

\begin{abstract}
El propósito de este artículo es analizar en el caso de Brasil los mecanismos de poder del impeachment, el lawfare y las fake news, mecanismos que ban sido también determinantes en otros procesos electorales recientes. Ello nos permite reflexionar sobre el actual escenario político latinoamericano, caracterizado por una mayoría de gobiernos de derecha liberal — conservadora o populista-identificados con políticas neoliberales.
\end{abstract}

Palabras clave: impeachment, lawfare, fake news, Brasil, América Latina.

Abstract: The purpose of this article is to analyze the powerful mechanisms of impeachment, lawfare, and fake news in Brazil. These mechanisms have been decisive in other electoral processes in recent times and allow us to consider the current political situation in Latin-America, which is mainly characterized by liberal right-wing conservative or populist governments identified with neoliberal politics.

Keywords: impeachment, lawfare, fake news, Brazil, Latin America 


\section{Introducción}

En la primera década del siglo xxi, América Latina se orientó a la izquierda del espectro político, con gobiernos antineoliberales y fuertes liderazgos, como el de Hugo Chávez, Lula da Silva, Néstor y Cristina Kirchner, Pepe Mujica, Evo Morales y Rafael Correa (Kessler, 2014).

La contraofensiva conservadora se impuso en la segunda década del nuevo siglo, con las victorias de Macri y de Bolsonaro, el giro del gobierno de Lenín Moreno y el aislamiento internacional del gobierno de Maduro a raíz de la elección de Trump. Fueron muchos los que se apresuraron a anunciar el comienzo de un largo ciclo histórico neoliberal en América Latina. Lo más paradójico de todo fue quizás que la derecha llegó al poder en países que habían vuelto a crecer, habían disminuido la desigualdad y tenían buenas relaciones de cooperación con sus vecinos. Países que habían logrado estabilidad política y convivencia pacífica y democrática entre las fuerzas políticas, sociales y culturales, con un Estado orientado a ser garante de los derechos de todos.

En este contexto, las derechas regionales, que suelen basar su discurso político en las ideas de libertad y república, lo que supondría el respeto a las instituciones y la división de poderes, desarrollaron en algunos países acciones vinculadas con la persecución política o lawfare de líderes populares. Colombia, como ejemplo extremo, destaca por tener una altísima tasa de asesinatos por motivos políticos.

No obstante, puede observarse que el actual ciclo neoliberal ha perdido fuerza y da la impresión de que será más corto que los anteriores: un primer ciclo iniciado en 1973 con el golpe de Estado de Augusto Pinochet en Chile, donde el neoliberalismo construyó su régimen más estable, que fue seguido por las dictaduras en toda la región; y un segundo ciclo que se prolongó durante la década de 1990.

Así, la actual ofensiva neoliberal ha ido revelando sus debilidades, empezando por el inesperado triunfo de López Obrador en México y su tardía incorporación al "ciclo progresista", $y$, posteriormente, por la victoria en primera vuelta de Alberto Fernández y de Cristina Kirchner. Y si bien lo sucedido a finales de 2019 en Bolivia y en Uruguay parecía cuestionar esta tendencia, la realidad nos demuestra lo contrario. Por una parte, si bien el candidato conservador Lacalle Pou ganó en segunda vuelta, también es cierto que se impuso por un margen más ajustado del esperado, a pesar de contar con el apoyo de los otros dos candidatos de la derecha uruguaya. A ello se suma en 2020 el triunfo del Frente Amplio en las elecciones municipales de Montevideo. Por otra, a pesar de que Evo Morales fue derrocado mediante un golpe de Estado, en las elecciones presidenciales celebradas en octubre de 2020, el candidato por el MAS Luis Arce ganó ampliamente en primera vuelta. Asimismo, parece que el rechazo abrumador a la Constitución heredada 
de Pinochet mediante el reciente plebiscito celebrado en Chile confirma dicha dirección.

No hay que olvidar que, mientras que el gobierno de Evo Morales hizo crecer la economía más que nadie en toda Latinoamérica y supo, además, traducir dicho crecimiento en una mejora del bienestar de la población, países como Perú, Colombia o Paraguay solo podían presumir de buenos indicadores macroeconómicos. Por su parte, la Argentina de Macri no disfrutó ni de una cosa ni de la otra.

Otra señal del debilitamiento del ciclo neoliberal en la región han sido las masivas movilizaciones en Ecuador, Chile y Colombia desencadenadas a finales del año 2019 y reprimidas con dureza. En este último país, las elecciones municipales también representaron una dura derrota para el actual presidente, Iván Duque, representante del uribismo, ya que salieron fortalecidos candidatos del campo popular, vinculados al nuevo líder de la izquierda, Gustavo Petro.

Por último, la liberación de Lula da Silva y su intención de luchar contra las arbitrariedades del gobierno de Bolsonaro representaron otro duro golpe a la restauración conservadora latinoamericana.

De esta forma, América Latina confirma las debilidades del neoliberalismo y evidencia que la derecha carece de alternativas y no ha aprendido nada del agotamiento de su modelo. Pese a ello, insiste en su política de ajustes fiscales y revela su incapacidad no solo para retomar el crecimiento económico y luchar contra el desempleo, sino también para conquistar bases de apoyo suficientes que le permitan tener gobiernos con estabilidad política. Las explosiones populares fueron la respuesta del pueblo a las medidas de ajuste fiscal, y han puesto en evidencia el modelo neoliberal de Moreno, de Piñera y de Duque.

Así, el tercer ciclo neoliberal se ha acortado notablemente porque el neoliberalismo ha demostrado tener poco que ofrecer a la inmensa mayoría de la población, que se había creído falsas promesas y había votado con la esperanza de una mejora frente a los límites del crecimiento evidenciados por los gobiernos populares, tanto por limitaciones propias como por los cambios en la economía mundial tras la crisis estadounidense de 2008. Buena parte de las clases bajas y medias confiaron en la promesa de que no iban a perder nada de lo que ya tenían, pero no votaron por la reducción de las funciones del Estado y de los servicios públicos y la caída tendencial de los salarios.

Las realidades de cada país son particulares, pero el escenario de fondo es el mismo: oligarquías que aplican programas de ajuste con el apoyo entusiasta de los Estados Unidos, recurriendo en algunos casos al FMI como herramienta para consolidar el sometimiento en el largo plazo a través del mecanismo del endeudamiento. La reacción se expresa en Perú a través de la crisis institucional; 
en Ecuador, Chile y Colombia, a través del estallido social. En Brasil se desdibuja la imagen de un presidente que aún no lleva ni dos años de mandato. Y si en Argentina no hubo estallido social con Macri fue porque el desarrollo de la crisis se demoró hasta 2018 y porque la sociedad política fue capaz de encontrar un camino institucional.

Las formas que adoptará el posneoliberalismo emergente son todavía una incógnita. El contexto internacional es muy diferente al de la primera década de este siglo: 1) no solo América Latina, sino todo el mundo está sumido desde hace meses en la pandemia del coronavirus, que conlleva profundas consecuencias sanitarias, sociales y económicas y puede provocar políticas impredecibles; 2) hoy no existe un ciclo expansivo en los precios de los commodities, que representan las principales exportaciones regionales; 3 ) los Estados Unidos han retomado su actividad contra los Gobiernos favorables a la redistribución y la emancipación y la identidad latinoamericanas del primer ciclo progresista, para reemplazarlos por Gobiernos neoliberales; y 4), sin embargo, los Estados Unidos han ido reduciendo su presencia económica en América Latina, de forma que China ha ido ganando influencia, hasta convertirse en el mayor socio comercial de toda la región.

\section{Impeachment, lawfare y fake news en Brasil}

En el marco de la contraofensiva conservadora en América Latina, que ha buscado restaurar Gobiernos neoliberales, es en Brasil donde el neoliberalismo cuenta con bases más frágiles para consolidarse y más dificultades para poner en práctica su programa. Los próximos años serán duros en cuanto a disputas políticas, pues no solo Brasil, sino, en cierta forma, también el destino del continente está en juego.

El cambio de signo político en Brasil tuvo lugar de forma paralela a una serie de fenómenos que ya se habían comenzado a observar en América Latina y el mundo. En el caso de Brasil, se encadenaron de tal manera que posibilitaron:

a) la caída de Dilma Rousseff mediante el impeachment y la llegada al poder de un defensor de las políticas neoliberales como Temer;

b) el proceso de lawfare que permitió encarcelar y apartar de las elecciones presidenciales a quien era el candidato con mayor intención de voto: Lula da Silva; $y$

c) la victoria de Bolsonaro en dichas elecciones a partir de un discurso populista de derecha y con el uso de nuevas tecnologías aplicadas a las fake news. 


\section{a) Impeachment o golpe blando}

Desde el inicio de este siglo, se han producido en América Latina siete intentos de golpes de Estado o de lo que se conoce recientemente como "golpes blandos", cuatro de los cuales han tenido éxito: contra Hugo Chávez (2002), Evo Morales (2008), Mel Zelaya (2009), Rafael Correa (2010), Fernando Lugo (2014), Dilma Rousseff (2016) y Evo Morales (2019).

El golpe de Estado que destituyó a Evo Morales es el eslabón más reciente de una serie de "golpes blandos" que comenzaron con el derrocamiento de Mel Zelaya, presidente de Honduras. Dichos golpes cada vez se fueron haciendo más sofisticados.

El primero, el de Honduras, fue un golpe latinoamericano tradicional y una parodia de legalidad propia de los denominados golpes blandos, que se caracterizan por acciones combinadas de los medios de comunicación, el sector económico-financiero dominante, el poder legislativo y el poder judicial, y por la injerencia de la embajada estadounidense. A diferencia de los golpes tradicionales, se coloca en el poder a un civil; en el caso de Honduras, Roberto Micheletti, presidente del Congreso Nacional, asumió la presidencia.

El siguiente golpe fue un juicio político exprés en Paraguay sin pruebas contra el presidente Fernando Lugo que supuso la violación de su derecho de defensa. El Congreso paraguayo decidió destituirlo por su "responsabilidad política” a raíz de un conflicto entre campesinos y terratenientes. En los enfrentamientos entre campesinos y policías, se produjeron diecisiete muertos. El juicio duró menos de cuarenta y ocho horas y Lugo tuvo menos de dos horas para defenderse. A falta de pruebas reales, fue destituido por el voto de 215 de los 225 congresistas paraguayos después de que la Corte Suprema rechazara la petición de aplazar el proceso.

En Brasil el golpe se tradujo en un proceso legal, aunque ilegítimo y sin fundamentos jurídicos. En este caso se respetaron los tiempos y rituales formales que establece la legalidad, utilizando el mecanismo constitucional del juicio político - impeachment-, pero se trató de un golpe blando por el uso desvirtuado que se hizo de dicho mecanismo (Breda, 2016). Dilma Rousseff fue acusada por una supuesta irregularidad administrativa y llevada a juicio político en 2016. Sin embargo, el Tribunal de Cuentas nunca antes había considerado irregular los decretos para reasignar recursos presupuestarios, aprobando sin objeciones las rendiciones de cuentas presidenciales. $\mathrm{Al}$ poco tiempo, la fiscalía brasileña determinó que no había existido delito y ordenó archivar la investigación. Pero el Congreso de Brasil ya había votado su destitución. Además, se violó el principio de no discriminación por razones políticas, ya que dicho mecanismo no se aplicó 
a su sucesor, Michel Temer, que había sido denunciado por los mismos hechos. En cuanto se votó la destitución, el Congreso sancionó la Ley 13.332/16, que de forma expresa legitimó el procedimiento de destitución de Dilma Rousseff.

En el último golpe de Estado, el de Bolivia, la parodia de legalidad no tardó en intentar hacerlo pasar simplemente como la renuncia de un presidente acorralado por las manifestaciones. Evo Morales, primer jefe de Estado indígena en Bolivia, en el poder desde hacía catorce años, buscaba un cuarto mandato con el aval de la referéndum de 2016. justicia boliviana, que lo habilitó para participar en los comicios tras su derrota en el Cabe recordar un hecho que contribuyó a este resultado: durante la campaña se difundió la fake new de que Evo Morales tenía un hijo no reconocido, lo que sirvió para desacreditarlo.

El expresidente de derecha Carlos Mesa (2003-2005) aparecía como el candidato opositor mejor posicionado para llegar a una eventual segunda vuelta. El proceso que terminó con la destitución del presidente boliviano comenzó tras las elecciones del 20 de octubre, cuando se acusó al Gobierno de fraude electoral. A partir de entonces la violencia de la oposición y la presión internacional de la derecha fueron en aumento. El día anterior a su renuncia, Morales convocó nuevas elecciones tras una auditoría de la OEA que detectó supuestas irregularidades en los comicios. Pero este anuncio no bastó a los líderes opositores, que volvieron a exigir su renuncia en medio de profundas tensiones y ataques directos a viviendas de funcionarios, hasta que los militares y la policía retiraron su apoyo al mandatario y forzaron su renuncia para "pacificar el país", por lo cual debió abandonar Bolivia y exiliarse en México para salvar su vida. Posteriormente viajaría a Argentina.

El golpe contra Evo Morales fue un golpe de Estado mediante un pronunciamiento militar. No hace falta que los tanques entren en la casa de gobierno para que un golpe sea un golpe. Asimismo, el hecho de que presentara su "renuncia" tampoco significa nada. Si así fuera, el golpe de 1955 sería simplemente la "renuncia” de Juan Domingo Perón en Argentina, y el de 1954 la "renuncia” de Jacobo Árbenz en Guatemala. La decisiva intervención de las fuerzas armadas o de seguridad marca una diferencia entre el golpe boliviano de 2019 y los numerosos casos de renuncia anticipada de un presidente acorralado por las manifestaciones, como las de los dos presidentes bolivianos anteriores, Gonzalo Sánchez de Lozada y Carlos Mesa. A diferencia de las destituciones de Fernando Lugo (juicio político exprés sin posibilidad de defensa), Dilma Rousseff (impeachment sin delito) y Pedro Kuczynski (renuncia ante la inminencia de impeachment), esta vez no se trató de un "golpe con adjetivos" (Malamud y Marsteintredet, 2020). 


\section{b) Lawfare}

Para el antropólogo John Comaroff, la condena a Lula da Silva es un claro ejemplo de lawfare ${ }^{1}$, fenómeno que forma parte de un nuevo campo de ensayo en América Latina. En el marco de la causa Lava Jato, el entonces juez Sergio Moro, y desde abril de 2020 exministro de Justicia de Bolsonaro tras su renuncia, condenó al líder del Partido de los Trabajadores (PT) por supuestamente recibir un departamento en la localidad paulista de Guarujá y beneficiarse de unas reformas en una casa de fin de semana en Atibaia. Ninguno de los dos inmuebles era de su propiedad.

La operación Lava Jato se inició en 2014 para investigar sobornos pagados por grandes empresas de la construcción a dirigentes políticos y funcionarios del entonces gobierno del PT para conseguir contratos de obra pública con la petrolera semiestatal Petrobras.

La causa Lava Jato se dirigía en un comienzo contra los funcionarios del PT, en el marco del acelerado proceso de pérdida de popularidad del Gobierno de Dilma Rousseff, que se sustentaba sobre un sistema de corrupción real. Surgida inicialmente como una forma de incidir en el desgaste de la gestión del PT y evitar su posible continuidad en la figura de Lula da Silva, la causa sin embargo se fue ampliando hasta abarcar buena parte de la clase política y empresarial brasileña. Más de ciento cincuenta políticos y empresarios han sido condenados, entre ellos el artífice del impeachment a Dilma Rousseff, Eduardo Cunha, con nada menos que veinticuatro años de prisión, y el empresario más importante del país, Marcelo Odebrecht, que pasó dos años en prisión preventiva.

En la sentencia, Moro acusó a Lula da Silva de "corrupción pasiva", y admitió que lo condenaba por "actos indeterminados" y que, a falta de pruebas, actuó "basado en convicciones". La defensa de Lula alegó que el expresidente nunca poseyó tal propiedad y que los denunciantes mintieron para obtener una reducción de pena.

Existen otras seis acusaciones contra Lula da Silva, aunque ninguna de ellas parece mucho más sólida jurídicamente que el endeble caso del departamento de Guarujá, el tríplex que la constructora OAS reformó por 300.000 euros en el año 2014, supuestamente como un soborno a cambio de obras adjudicadas por Petrobras ocho años antes, cuando Lula da Silva era presidente. Según la escritura, el apartamento no pertenecía entonces a Lula da Silva y ha sido vendido por su propietario legal. Pese a ello, Moro sentenció al expresidente a nueve años de cárcel por corrupción pasiva y blanqueo de dinero, una pena que un segundo tribunal elevó a doce años.

1 "Harvard Professor Sees 'Presumption of Guilt' Used Against Ex-President Lula", Folha de S. Paulo, 11/04/2016. 
La acusación descansa en las declaraciones del presidente de la constructora OAS, Leo Pinheiro, que fue encarcelado en 2014 por corrupción. A cambio de inculpar a Lula da Silva, Pinheiro logró reducir su pena a la mitad y luego fue puesto en libertad. Algunas de las conversaciones intervenidas dejan entrever que, tras negarse a implicar a Lula durante meses, Pinheiro cambió su testimonio al comprobar que sería la única forma de pactar una reducción de la pena con los fiscales de Lava Jato.

Además de inhabilitarlo para presentarse como candidato a presidente, la Justicia prohibió a Lula da Silva conceder entrevistas durante la campaña electoral para las presidenciales, en las que Bolsonaro fue elegido presidente de Brasil.

Como sostiene Geraldo Carreiro de Barros Filho (2017), el concepto lawfare se refiere a la utilización de los jueces como herramienta de persecución política por medio de la creación de "maxiprocesos" que tienen un gran impacto en la opinión pública, por ejemplo mediante la transmisión en vivo de las detenciones, y por ello exigen una relación fluida entre el Poder Judicial y los medios de comunicación.

Estos procesos utilizan normalmente tipos penales abiertos (en Brasil se los denomina "organización criminal") que permiten englobar en una misma causa judicial a imputados con diferentes características. Como normalmente las acusaciones se basan en crímenes contra la Administración pública difíciles de probar, el Poder Judicial suele recurrir a recursos procesales controvertidos, como la "delación premiada” en el caso Brasil. Estas figuras reducen las garantías de los acusados $y$, junto con el abuso de la prisión preventiva, otorgan a los jueces un amplio margen de discrecionalidad, obteniéndose en muchos casos confesiones bajo coerción. Además, el efecto del lawfare es tanto político como judicial, ya que también importa el impacto que produce la causa a medida que avanza. Dicho impacto se amplifica mediante el relato mediático hegemónico, con la corrupción en cuanto elemento de legitimación.

En conclusión, a pesar de no haber pruebas fehacientes de ningún delito, Lula da Silva fue condenado a veinticinco años de prisión. Los jueces desoyeron la recomendación de la ONU, que pedía se le permitiera participar en las elecciones del 7 de octubre de 2018 porque aún faltaban dos instancias en su juicio. Así, el lawfare conllevó un fraude electoral porque se le prohibió por decisión judicial ser candidato a la presidencia. Hasta ese momento Lula da Silva era el único aspirante que en las encuestas de opinión tenía más del $40 \%$ de intención de voto (Crespo y Meireles, 2018). Por ello, no sorprende la designación del juez Moro como ministro de Justicia y Seguridad Pública del gobierno de Bolsonaro, beneficiario último de todo ese proceso. 
Se tuvo que esperar al 8 de noviembre de 2019 para que el expresidente saliera de prisión tras permanecer recluido desde abril de 2018. La Corte Suprema lo autorizó a esperar en libertad hasta agotar todos los recursos a los que tiene derecho a apelar para revisar sus condenas. Lula da Silva cumplía una pena de ocho años y diez meses de prisión por corrupción y lavado de dinero. La sentencia ha sido ratificada en tres instancias, por lo que tan solo le quedan pendientes los recursos que elevó ante la Corte Suprema.

En julio de 2018 ya había sido absuelto en otra causa donde se lo acusaba de obstrucción a la justicia. En el marco de ese caso se intentó demostrar que había comprado el silencio de un ejecutivo de Petrobras para evitar que lo denunciara por los desvíos en la petrolera. Y en diciembre de 2019 se archivó una de las causas que más impacto causó en 2017 tras la destitución de Rousseff, por la que se la acusaba a ella y a Lula da Silva de desviar recursos de la petrolera Petrobras y de otras empresas estatales para financiar la campaña del Partido de los Trabajadores (PT), primero con Lula (2003-2010) y después con Rousseff (20112016). De este modo, fueron absueltos del cargo de asociación ilícita, ya que habían usado como base esa causa para generar otras con las que acusaron a varios miembros del PT. Los acusados fueron declarados inocentes dos meses después de que la propia Fiscalía solicitara su absolución sumaria tras reconocer que no existían elementos configuradores de la existencia de una organización criminal. De este modo, el juez del caso llegó a la conclusión de que el proceso tan solo buscaba criminalizar la actividad política de los expresidentes de Brasil. Desde el entorno de Lula da Silva se reforzó la idea de que está siendo perseguido, que es víctima de lawfare destinado a evitar su regreso al poder. De esta manera se cerró uno de los nueve procesos judiciales abiertos en su contra.

Sin embargo, no todos los juicios se están resolviendo en favor del expresidente. También a finales del año 2019, Lula da Silva fue condenado a diecisiete años de prisión por corrupción en segunda instancia: una cámara de apelaciones ratificó el fallo inicial en el caso, ya mencionado, de las obras realizadas por empresas constructoras como OAS y Odebrecht en una casa de Atibaia.

\section{c) Nuevas tecnologías, fake news y posverdad}

Las medidas económicas de inspiración neoliberal propuestas por Bolsonaro parecen ser rechazadas por la mayor parte de la población brasileña, ya que el Gobierno de Temer, pese a una fuerte oposición y a no generar crecimiento, ya las venía adoptando. ¿Cómo se explica entonces la victoria de Bolsonaro en las elecciones presidenciales? 
Un elemento a tener en cuenta es que las personas parecen estar decidiendo su voto sobre la base de emociones - como rabia, miedo y frustración - fuertemente amplificadas por las redes sociales, que difunden tanto verdades como mentiras y dudosas interpretaciones. En este contexto, el debate sobre los problemas reales y los costos y beneficios de las diferentes alternativas socioeconómicas queda relegado.

Los mensajes falsos se diseñan desde centros de poder real, con una diagramación estratégica, que usa diseminación geométrica a partir del empleo de robots, de inteligencia artificial, hacia miles y miles de personas, que replican hacia otras miles por emocionalidad, por baja capacidad de mirada crítica.

Regular los troles y los bots, sin embargo, no es tarea fácil. Además de que quienes están detrás de las cuentas han perfeccionado un sistema para no ser descubiertos, hay que tener en cuenta que no son solo los usuarios falsos los que propagan las noticias falsas. El problema reside en que a las campañas orquestadas se van sumando internautas comunes, lo que no solo no se puede regular, sino que tampoco se puede prever sus efectos.

Para que todo eso suceda, es necesario que los usuarios de las redes compartan unos mismos valores y accedan a aquella información que confirme sus creencias. A ello contribuye también la percepción de que se trata de una iniciativa individual, si bien confirmada por el algoritmo.

Las fake news son noticias falsas creadas de manera intencionada y engañosa para difundir y promover la confusión, para desestabilizar, para generar adhesiones a discursos de odio, para manipular a la opinión pública y, en última instancia, para obtener beneficios políticos y económicos.

El concepto de posverdad está vinculado a estos fenómenos, en la medida en que caracteriza a la distorsión deliberada de una realidad en la que los hechos objetivos tienen menos influencia que las apelaciones a las emociones y a las creencias personales, con el fin de crear y modelar la opinión pública e influir en las actitudes sociales (Rubio, 2017). En este sentido, se denomina política de la posverdad a aquella en la que el debate se enmarca en apelaciones a emociones y se desconecta de los detalles de la política pública.

Asimismo, el surgimiento de la política de la posverdad coincide con la polarización política de las sociedades, como ha sucedido en Brasil en los últimos años. Bolsonaro recibió un amplio apoyo financiero y tecnológico para su campaña que no solo incrementó su presencia como candidato entre la población, sino que también fomentó y estimuló un discurso populista basado en el odio que polarizó a la sociedad, a la manera del análisis de Laclau (2005). De hecho, durante la campaña electoral, Fernando Haddad, el candidato presidencial del PT, acusó 
a Bolsonaro de estar detrás de las fake news en su contra. El proceso electoral fue cuestionado por el uso ilegal de robots que difundían millones de fake news contra el PT en las redes sociales. El Tribunal Superior Electoral no procedió con imparcialidad durante el proceso, ya que permitió la libre circulación de las fake news, al declararse incapaz de controlar los contenidos difundidos en la plataforma WhatsApp (Crespo y Meireles, 2018).

A modo de ejemplo, estas fueron algunas de las fake news más difundidas a través de las redes sociales contra Haddad:

1. "El 'kit gay' para niños de 6 años distribuido en las escuelas". En realidad, se trató de un proyecto llamado Escuela Sin Homofobia, que el Ministerio de Educación, entonces bajo la gestión de Haddad, presentó en 2011 con el apoyo de diversas ONG, pero que no llegó a ser implantado ("kit gay" fue el apodo dado por sus detractores).

2. "El hombre que apuñaló a Bolsonaro está afiliado al PT y aparece en una foto con Lula". En realidad, no estaba afiliado al PT y la foto con Lula fue un fotomontaje.

3. "La señora agredida por ser votante de Bolsonaro". En realidad, era una foto de la actriz Beatriz Segall en 2013, tras caerse en la calle.

4. "Haddad defiende el incesto y el comunismo en uno de sus libros". Falso.

5. "Si Haddad llega al poder, pretende legalizar la pedofilia". Falso.

6. "Si gana el PT, los padres tendrán que entregar a sus hijos al Estado para que este decida su orientación sexual". Falso.

Además, es interesante destacar que Bolsonaro ha utilizado personalmente la estrategia de las fake news como política de comunicación oficial, incluso tras la campaña electoral. Según las revelaciones de la agencia de verificación de datos Aos Fatos ${ }^{2}$, durante las primeras diez semanas de su mandato, Bolsonaro hizo 149 declaraciones pasibles de chequeo, de las cuales 82 eran completamente falsas o presentaban algún grado de error. Esto significa que, de cada 10 declaraciones del presidente, casi 6 eran falsas o distorsionadas. También significa que Bolsonaro proporcionó, de media, una información equivocada por día desde que se convirtió en presidente, fundamentalmente sobre economía y cuestiones ideológicas.

A partir de todo ello surge la pregunta: ¿cómo se puede escapar de las manipulaciones y las fake news de los políticos y de las corporaciones mediáticas? Ciertamente, se trata de un problema de difícil solución.

2 "Em dez semanas como presidente, Bolsonaro deu uma declaração errada por dia", Aos Fatos, 11/03/2018. 


\section{Lawfare en Brasilः las filtraciones del sitio The Intercept}

La crisis de credibilidad de la investigación del proceso de anticorrupción conocido como Lava Jato allanó el camino a la puesta en libertad de Lula da Silva, tras 580 días en prisión. El expresidente, de setenta y cuatro años, que estuvo encarcelado en un calabozo de quince metros cuadrados, no se cansó de insistir en que no aceptaría un perdón por motivos humanitarios. Lo único que le valía era la anulación del juicio y la declaración de su inocencia.

A partir del 9 de junio del año 2019, el medio digital The Intercept empezó a publicar conversaciones de la aplicación de mensajería Telegram entre el exjuez Moro y miembros de la investigación Lava Jato, coordinada por el procurador Deltan Dallagnol. Los mensajes, grabaciones de audio, vídeo y fotos, enviados por una fuente anónima, expusieron irregularidades en la mayor causa judicial de la historia de Brasil. Los artículos de The Intercept fueron firmados por el periodista norteamericano Glenn Greenwald, el mismo que en 2013 publicó los papeles secretos obtenidos por Edward Snowden en la agencia NSA, reportaje por el cual obtuvo el premio Pulitzer.

Las filtraciones del sitio The Intercept mostraron que el exjuez y actual ministro de Justicia de Brasil, junto a Deltan Dallagnol, dirigieron la causa Lava Jato para perjudicar al Gobierno de Dilma Rousseff, impedir la candidatura presidencial de Lula Da Silva y allanar el camino para la victoria de Bolsonaro. La causa Lava Jato, con el pretexto de combatir la corrupción, no se ha ajustado a derecho con una manifiesta intencionalidad política, ya que ha buscado objetivos políticos y electorales a través de procedimientos ilegales. Por ejemplo, entre los materiales aparecidos hay mensajes entre fiscales de la causa Lava Jato sobre cómo impedir que Lula da Silva conceda una entrevista a los diarios El País de España y Folha de S. Paulo antes de las elecciones en las que fue elegido Bolsonaro. Recientemente, en abril de 2019, tras más de tres meses de Bolsonaro en la presidencia, el Supremo Tribunal Federal de Brasil anunció que el expresidente Lula da Silva podía dar entrevistas desde la prisión de Curitiba.

El exjuez Moro se ha quejado de que The Intercept violó su privacidad, pero en plena campaña electoral brasileña filtró el contenido de la delación premiada al exministro de Justicia de Lula, Antonio Palocci, para favorecer las posibilidades electorales de Bolsonaro. En una de las conversaciones transcritas por The Intercept, el entonces juez Moro le dicta al jefe de los fiscales Dallagnol los pasos a dar en uno de los tantos operativos de Lava Jato. Y en otra reprende al fiscal por la 
demora a la hora de llevar a cabo nuevas acciones, generalmente espectaculares, que siempre eran amplificadas por los medios de comunicación hegemónicos.

Las revelaciones publicadas por The Intercept evidencian las manipulaciones políticas y jurídicas de la operación Lava Jato. En las conversaciones mantenidas entre los fiscales del Lava Jato, se afirma que entregaron a la prensa los audios de conversaciones telefónicas entre Lula da Silva y la entonces presidenta Dilma Rousseff cuando estaba por nombrar al nuevo jefe de la Casa Civil en marzo de 2016. La filtración terminó siendo el elemento central de un plan político y mediático que llevó a la destitución de Rousseff, sin que hubiera cometido actos inconstitucionales que justificaran su salida del cargo.

Las revelaciones hechas por The Intercept Brasil sobre las maniobras de los jefes de la causa Lava Jato han tenido resultados devastadores para esa gran operación jurídico-político-mediática de la derecha brasileña debido a la calidad de la información aportada. Ha dejado al descubierto la manipulación de las leyes, la promiscuidad de sus formas de actuación y el carácter partidario de la persecución a Lula da Silva como su objetivo fundamental. Tanto que el propio Supremo Tribunal Federal tomó nota de las revelaciones y los abogados del expresidente las anexaron en el recurso para la anulación de lo actuado en dicha causa.

En definitiva, los diálogos revelados por The Intercept evidencian que los fiscales no son actores imparciales y apolíticos, sino que más bien parecen motivados por convicciones ideológicas y movidos por el deseo de que el PT no vuelva al poder. Y dejan al descubierto cómo el exjuez Moro dirigió su investigación para detener al expresidente y evitar que se presentara a las últimas elecciones presidenciales de Brasil.

El debilitamiento de Sergio Moro por las denuncias de The Intercept debilitó el proyecto de la derecha, hasta el punto de que el paquete que envió al Congreso antes de su renuncia como ministro, que planteaba duras medidas represivas, no llegó a ser aprobado.

\section{4. ¿Persecución política o lucha contra la corrupción? Algunos casos latinoamericanos}

Se suele afirmar que en América Latina ha habido un sistema judicial que ha actuado para perseguir a dirigentes populares que han liderado la década progresista en América Latina. El lawfare explica también las acusaciones judiciales contra otros expresidentes latinoamericanos con el objetivo de apartarlos de las elecciones presidenciales: Rafael Correa terminó exiliado, Cristina Kirchner fue 
amenazada sistemáticamente y a Evo Morales no se le permitió presentarse a las elecciones convocadas para el año 2020.

En el caso de Cristina Kirchner, no pudieron apartarla del camino a un nuevo Gobierno popular porque las causas judiciales en su contra son endebles y las pruebas inexistentes; tampoco pudieron porque el pueblo la eligió como senadora parlamentaria, lo que la convertía en aforada, y porque se inició la unificación del peronismo.

En Argentina existen evidencias tanto de funcionarios del Gobierno kirchnerista implicados en hechos de corrupción como de operaciones judiciales, mediáticas y de inteligencia para relacionar la gestión kirchnerista con hechos de corrupción en la obra pública. Un ejemplo es la causa iniciada por la denuncia por extorsión del productor agropecuario Pedro Etchebest, que aportó catorce horas de audios, filmaciones y fotografías, lo que llevó al descubrimiento de una red de espionaje integrada por agentes orgánicos o inorgánicos de los servicios de inteligencia, y de operaciones ilegales vinculadas con el poder judicial, ministerios, fuerzas de seguridad, poderes políticos y medios de prensa.

Todo ello se evidenció también en la articulación de las declaraciones de los llamados "arrepentidos" por parte del Gobierno de Mauricio Macri. Por ejemplo, la exabogada de Leonardo Fariña, arrepentido colaborador, entregó al juez Ramos Padilla los mensajes de WhatsApp intercambiados con el ministro de Justicia, Germán Garavano, para la reunión donde se negoció la declaración de este financista contra Cristina Kirchner y los emails que recibía Fariña con el guion de lo que debía decir para orientar la causa hacia el Gobierno kirchnerista y la obra pública.

Por su parte, en las elecciones presidenciales ecuatorianas de 2017 parecía que había dos caminos: el continuismo de las transformaciones realizadas por el Gobierno de Rafael Correa durante diez años o el retorno neoliberal con el banquero más grande de Ecuador, Guillermo Lasso. Aunque el candidato de Alianza País, que además había sido vicepresidente de Rafael Correa, Lenín Moreno, ganó en segunda vuelta, poco después se volvió en contra de la Revolución Ciudadana.

Lenín Moreno llegó al poder con los votos de Rafael Correa, pero luego realizó un giro que lo llevó a apoyar al Fondo Monetario Internacional, a reconocer y recibir al autoproclamado presidente venezolano Juan Guaidó y a ser un abanderado de los postulados de Unasur.

Moreno se sumó a las acusaciones de la oposición contra el vicepresidente, Jorge Glas, y sobre supuesta corrupción en el Gobierno de Correa. Así, dichas acusaciones comportaron la condena de Glass, su destitución como vicepresidente y su encarcelamiento. 
Y para completar el giro hacia la derecha, el Gobierno de Moreno pasó a defender un argumento propio de la derecha: los problemas de Ecuador serían culpa de los gastos excesivos del Gobierno de Correa y el endeudamiento correspondiente. Además, la derecha fue recompensada con cargos en el Gobierno y formó una alianza de hecho con Lenín Moreno.

Sin embargo, se trataba de un Gobierno inestable que perdió sus bases populares, sin lograr sustituirlas por otro tipo de apoyo, como pudo verse en el contexto de las movilizaciones desarrolladas a finales de 2019.

Como sucedió con Lula da Silva en Brasil y se intentó con Cristina Kirchner en Argentina, fue indispensable sacar a Rafael Correa de la lucha política legal del país, con acusaciones burdas de una supuesta responsabilidad del expresidente en el intento de secuestro de un diputado de un partido de la derecha que se había refugiado en Colombia. Correa fue juzgado y condenado en ausencia, y finalmente se asiló en Bélgica. El Gobierno de Lenín Moreno intentó que Scotland Yard cumpliera una orden internacional de detención, pero recibió una respuesta negativa, ya que se alegó que Correa había sido víctima de un proceso en el que no se contemplaron las condiciones legales de defensa. Queda en evidencia que Rafael Correa y Jorge Glas también han sido víctimas del lawfare.

Se trataría, pues, de un mecanismo de las élites contra los partidos y líderes populares, de la derecha contra la izquierda. Sin embargo, el lawfare es una herramienta que puede ser utilizada por Gobiernos populares de tendencia autoritaria, como en Venezuela, donde el chavismo controla el poder judicial, aunque no el poder mediático, que está concentrado en gran parte en medios de comunicación privados opositores al Gobierno.

Aun así, el sesgo ideológico es indiscutible en la mayoría de los casos debido a que los siguientes tres componentes del lawfare, en la mayoría de los países de América Latina, están dominados por sectores conservadores de derecha:

1. el poder judicial, conservador en sí mismo;

2. el poder mediático, que en América Latina está concentrado en corporaciones con intereses oligopólicos en la economía de cada país; y

3. los servicios de inteligencia, brazo operativo que provee de material para las campañas de desprestigio, influidos por intereses extranjeros, especialmente por Estados Unidos.

A pesar de todos estos argumentos, no por ello deben minimizarse políticamente los delitos cometidos durante el ciclo de Gobiernos progresistas en América Latina. Como plantea Pablo Stefanoni ${ }^{3}$, la transparencia es actualmente una demanda general en las sociedades latinoamericanas que además puede ser ca-

$3<$ http://revistaanfibia.com/ensayo/cuando-se-jodio-el-progresismo/> 
pitalizada por la izquierda, como demuestra la exitosa campaña "honestista" que llevó a López Obrador a la presidencia de México.

La pregunta, llegados a este punto, es: ¿se trata en todos los casos de lawfare, de persecución política? ¿O las evidencias permiten a veces identificar casos judiciales legítimos dirigidos a luchar contra la corrupción?

Por ejemplo, ¿el proceso contra Pérez Molina en Guatemala puede ser definido como lawfare? En este sentido, más recientemente Temer en Brasil fue detenido de manera preventiva y a los pocos días puesto en libertad en una causa por el desvío de unos 500 millones de dólares de obra pública para su partido, el Movimiento Democrático Brasileño. Muchos analistas plantean que se trató de una maniobra judicial-mediática para contrarrestar el derrumbe de la popularidad de Bolsonaro durante sus primeros tres meses en el poder y sus enfrentamientos con el Poder Legislativo.

Incluso, las denuncias de Odebrecht salpicaron a otros expresidentes brasileños, y, si bien los juicios que contenían citaciones contra José Sarney (1985-1990) y Fernando Henrique Cardoso (1995-2003) ya fueron archivados, existe una investigación basada en denuncias contra Fernando Collor de Mello (1990-1992) que sigue en curso. Collor está imputado en un juicio ante el Supremo Tribunal Federal, acusado de recibir más de 30 millones de reales (7,6 millones de dólares) en sobornos por negocios de BR Distribuidora, que no tiene relación directa con Odebrecht.

Quizás el caso más dramático haya sido el del expresidente peruano Alan García, que se suicidó cuando la policía llegó a su domicilio con una orden para detenerlo bajo la acusación de haber recibido sobornos de la constructora brasileña Odebrecht. Su caso se suma a una serie de investigaciones por corrupción que afectan a expresidentes y funcionarios de toda la región.

En abril de 2015 Odebrecht se posicionó como la mayor constructora de América Latina. Tenía obras en todo el continente y acumulaba ganancias récord. Sin embargo, a medida que avanzaban las investigaciones de la operación Lava Jato la empresa empezó a colaborar con la Justicia. Así, Odebrecht confesó que diez países latinoamericanos recibieron sobornos millonarios a cambio de contratos de infraestructura pública entre 2001 y 2016. La compañía pagó sobornos para obtener contratos en Argentina, Brasil, Colombia, República Dominicana, Ecuador, Guatemala, México, Panamá, Perú y Venezuela. Queda por determinar qué grado de responsabilidad recae sobre los diferentes expresidentes y funcionarios de cada país.

En Perú, por su parte, los exmandatarios que han sido acusados de corrupción son Alberto Fujimori (1990-2000), Alejandro Toledo (2001-2006), Alan 
García (1990-1985 y 2006-2011), Ollanta Humala (2011-2016) y Pedro Pablo Kuczynski (2016-2018).

Fujimori es un caso anterior al escándalo de Odebrecht. En 2009 el expresidente reconoció el delito de peculado al haberse apropiado de 15 millones de dólares de las arcas nacionales para entregarlos a su exasesor, Vladimiro Montesinos, por el que se le impusieron siete años y seis meses de prisión.

En lo que respecta a Odebrecht, la empresa brasileña admitió que pagó un total de 29 millones de dólares en sobornos a funcionarios peruanos para adjudicarse obras públicas entre 2005 y 2014, período que abarca los Gobiernos de Toledo, García y Humala. Kuczynski ofreció su renuncia antes de que lo destituyera el Congreso, convirtiéndose en el político de más alto nivel en caer por el escándalo cuando aún ocupaba su cargo.

Así, el actual presidente de Perú, Martín Vizcarra, llegó imprevistamente al cargo, sin el voto popular, sin partido y sin bancada parlamentaria, pero en menos de un año consiguió un alto nivel de popularidad, logró imponerse ante un Congreso opositor dominado por un fujimorismo desestabilizador que parecía todopoderoso e impulsó reformas políticas y judiciales. Lo consiguió levantando la bandera de la lucha contra la corrupción, lo que lo puso en sintonía con la indignación ciudadana en un país con casi toda su clase política manchada por acusaciones de corrupción. También gracias a su enfrentamiento con el fujimorismo y con el Partido Aprista del expresidente Alan García, que simbolizan la corrupción política.

Así, convocó un referéndum para cuatro reformas constitucionales que incluían la prohibición de la reelección de los desacreditados congresistas, lo que despertó el entusiasmo popular y elevó su nivel de aceptación a más del $60 \%$. En el referéndum de diciembre de 2018, más de un $80 \%$ lo respaldó en los cuatro temas sometidos a consulta, con lo que obtuvo en las urnas la legitimidad que le faltaba.

Mediante el referéndum también se aprobó establecer limitaciones y controles al financiamiento privado de los partidos políticos. Ello tiene más relevancia ahora que los últimos cuatro presidentes y la excandidata presidencial Keiko Fujimori son investigados judicialmente por lavado de activos por el financiamiento ilegal de sus campañas. Con esta decisión, se prohíbe en los medios de comunicación la publicidad pagada, que se limitará a los espacios otorgados por el Estado.

La otra reforma aprobada con el referéndum crea la Junta Nacional de Justicia para nombrar y destituir jueces y fiscales. Se trata de una propuesta lanzada después de que se pusiera en evidencia la existencia de una mafia judicial con conexiones políticas, especialmente con el fujimorismo y el expresidente Alan 
García, en la que se vieron envueltos los integrantes del organismo predecesor de esta nueva Junta.

Si bien el Gobierno de Vizcarra es progresista respecto a los derechos de la mujer y en temas de género, aunque no llega a aceptar cuestiones como el aborto, en lo económico representa el continuismo de la política neoliberal. De hecho, el respaldo popular a Vizcarra no es un apoyo a su política económica, ya que, si bien la economía ha comenzado a crecer, se mantienen serios problemas de desempleo, desigualdad y exclusión.

Otro aspecto negativo de su gestión es la política exterior de su Gobierno, pues la política exterior peruana nunca había estado tan alineada con los intereses de Estados Unidos como en la actualidad, lo que se constata claramente en su posicionamiento respecto a la cuestión venezolana y en su alineamiento con los otros Gobiernos conservadores del Grupo de Lima.

Por último, es importante destacar que la experiencia a partir de la cual se construyeron los procesos judiciales latinoamericanos es el proceso Mani Pulite italiano, la megacausa sobre la cual el exjuez Moro escribió un elogioso artículo académico antes de iniciar la suya y llevar a Lula da Silva a prisión (Solano Gallego, 2018). Pero en América Latina cuando se habla de lawfare muchas veces se destaca la influencia norteamericana: algunas modificaciones en los códigos penales y ciertas innovaciones procesales tienen su origen en los Estados Unidos, y diferentes agencias de su Gobierno suelen invitar a jueces y fiscales latinoamericanos a cursos y seminarios de formación, como es el caso del exjuez Moro, que realizó incontables viajes a Estados Unidos para asistir a cursos y dar conferencias. Así, mientras ejercía la magistratura desde el sur de Brasil, también modeló su perfil jurídico e ideológico.

Por ello, a muchos dirigentes democráticos hoy les preocupa el fantasma de la Escuela de las Américas, que formó a los militares golpistas en la década de 1970, y del Plan Cóndor, que coordinó a las dictaduras para que colaboraran en labores de inteligencia y secuestro y asesinato de opositores en el territorio de cualquiera de esos países. Este fantasma estaría representado por el nuevo rol de los Estados Unidos a la hora de fijar la doctrina a seguir para muchos funcionarios judiciales del continente, y Sergio Moro es un ejemplo de ello. La estrecha relación entre el ministro de Bolsonaro y los Estados Unidos explica en gran medida por qué la operación Lava Jato dejó en evidencia que su objetivo político era la proscripción de Lula da Silva. 


\section{Conclusiones}

El escenario político latinoamericano de los últimos años se ha caracterizado por un grupo mayoritario de países con Gobiernos impulsores del recetario neoliberal. Debido a ello ya no se tuvo que comparar lo realizado por los gobiernos progresistas frente a lo hecho por los gobiernos neoliberales de los años 1990, sino que la comparación ha sido con la misma realidad contemporánea, con el nuevo escenario político latinoamericano. Como ya se ha mencionado, en la última década se ha producido un vuelco a la derecha en muchos países de América del Sur (Oliver, 2016), poniendo fin al ciclo de Gobiernos progresistas como un bloque regional. Bolivia, Uruguay y Venezuela fueron los países que venían manteniendo vivo el ciclo de Gobiernos de izquierda y centroizquierda en aquellos años, hasta el golpe de Estado contra Evo Morales y la derrota en segunda vuelta del Frente Amplio. No obstante, la derechización de América Latina no ha podido consolidarse por la llegada al poder de López Obrador en México, del peronismo en Argentina y, más recientemente, del MAS en Bolivia.

La orientación político-ideológica de la agenda de los Gobiernos latinoamericanos está vinculada con políticas expansivas y neodesarrollistas, o bien con políticas de ajuste de tipo neoliberal. De hecho, el modelo de desarrollo planteado está conectado a una decisión política determinada en función de diferentes perspectivas ideológicas.

La pregunta que es relevante plantearnos a principios del 2021 es si América Latina renovará o dará por terminado el ciclo protagonizado por Hugo Chávez, Lula da Silva, Néstor y Cristina Kirchner, Pepe Mujica, Evo Morales y Rafael Correa.

\section{Bibliografía}

Almagro Castro, D. (2017). "Tragedia y farsa en Brasil: los procesos de impeachment a Dilma Rousseff y Michel Temer". Cuadernos Manuel Giménez Abad, 14: 162-173.

Bielsa, R. y Peretti, P. (2019). Lawfare: guerra judicial-mediática. Del Primer Centenario a Cristina Fernández de Kirchner. Buenos Aires: Ariel.

BredA, T. (2016)."Brasilः crónica de un impeachment anunciado. Los colores de un país escindido". Nueva sociedad, 263: 4-18.

Brunet, I. y Böcker, R. (2013). Capitalismo global: aspectos sociológicos. Madrid: Grupo 5. 
Carreiro de Barros Filho, G.; de Albuquerque Farias, A. y Farias de Oliveira, G. (2015). "Consideraçóes sobre o Instituto do Lawfare". Id on Line Multidisciplinary and Psycology Journal, 33 (10): 363-369.

Crespo, R. y Meireles, M. (2018). "Brasil 2018: Réquiem de la democracia”. Revista Memoria, 268 (4), 64-66.

García Linera, Á. (2004). Sociología de los movimientos sociales en Bolivia. La Paz: Diakonia, Oxfam y Plural.

Kessler, D. (2014). Controversias sobre la desigualdad. Argentina 2003-2013. Buenos Aires. Fondo de Cultura Económica.

Laclau, E. (2005). La Razón populista. México D.F.: Fondo de Cultura Económica.

Malamud, A. y Marsteintredet, L. (2020)."Golpes con adjetivos: ¿precisión o confusión?". Análisis Carolina, 5: 1-13.

Ríos Vera, J. L. (2018). “Tres etapas del golpe 'blando' en Brasil”. Revista de Ciencias Sociales, 43 (31): 183-204.

Rubio, D. (2017). “La política de la posverdad”. Politica exterior, 176 (31):58-67.

Solano Gallego, E. (2018). “Impeachment, Lava Jato y elecciones". Política exterior, 185 (32): 72-80.

Svampa, M. (2015). "América Latina: de nuevas izquierdas a populismos de alta intensidad". Revista Memoria, 256 (4): 32-37.

Valadier, P. (2017). "La posverdad, peligro para la democracia”. Revista de Fomento Social, 72 (2): 297-304. 